\title{
Acute Respiratory Distress Syndrome: Pathophysiology and Therapeutic Options
}

\author{
Charalampos Pierrakos ${ }^{\mathrm{a}}$, Menelaos Karanikolas ${ }^{\mathrm{b}}$, Sabino Scolletta ${ }^{\mathrm{c}}$, Vasilios Karamouzos ${ }^{\mathrm{d}}$, \\ Dimitrios Velissaris ${ }^{\mathrm{e}, \mathrm{f}}$
}

\begin{abstract}
Acute Respiratory Distress Syndrome (ARDS) is a common entity in critical care. ARDS is associated with many diagnoses, including trauma and sepsis, can lead to multiple organ failure and has high mortality. The present article is a narrative review of the literature on ARDS, including ARDS pathophysiology and therapeutic options currently being evaluated or in use in clinical practice. The literature review covers relevant publications until January 2011. Recent developments in the therapeutic approach to ARDS include refinements of mechanical ventilatory support with emphasis on protective lung ventilation using low tidal volumes, increased PEEP with use of recruitment maneuvers to promote reopening of collapsed lung alveoli, prone position as rescue therapy for severe hypoxemia, and high frequency ventilation. Supportive measures in the management of ARDS include attention to fluid balance, restrictive transfusion strategies, and minimization of sedatives and neuromuscular blocking agents. Inhaled bronchodilators such as inhaled nitric oxide and prostaglandins confer short term improvement without proven effect on survival, but are currently used in many centers. Use of corticosteroids is also important, and appropriate timely use may reduce mortality. Finally, extra corporeal
\end{abstract}

Manuscript accepted for publication December 1, 2011

${ }^{a}$ Intensive Care Department, Brugmann University Hospital, Brussels 1030, Belgium

${ }^{b}$ Department of Anesthesiology, Washington University School of Medicine, St. Louis, Missouri, USA

${ }^{c}$ Department of Surgery and Bioengineering, Unit of Cardiothoracic Anesthesia and Intensive Care, University of Siena, Italy

${ }^{\mathrm{d}}$ Department of Internal Medicine, University Hospital of Patras, Rio, Greece

${ }^{\mathrm{e}}$ Department of Anesthesiology and Critical Care Medicine, University Hospital of Patras, Rio, Greece

${ }^{\mathrm{f}}$ Corresponding author: Dimitrios Velissaris.

Email: dimitrisvelissaris@yahoo.com

doi:10.4021/jocmr761w oxygenation methods are very useful as rescue therapy in patients with intractable hypoxemia, even though a survival benefit has not, to this date been demonstrated. Despite intense ongoing research on the pathophysiology and treatment of ARDS, mortality remains high. Many pharmacologic and supportive strategies have shown promising results, but data from large randomized clinical trials are needed to fully evaluate the true effectiveness of these therapies.

Keywords: ARDS; Pathophysiology; Treatment

\section{Introduction}

In 1821, Laennec described a new syndrome characterized by pulmonary edema without heart failure [1]. Subsequently, several terms, such as "double pneumonia", "shock lung" and "post traumatic lung" have been used to describe this syndrome. The term "Acute Respiratory Distress Syndrome" was first used in 1967 to describe a distinct clinical entity characterized by acute abnormality of both lungs [2].

In 1994, the American-European Consensus Conference on ARDS established criteria for the diagnosis of ARDS. These criteria include acute onset, bilateral lung infiltrates, no evidence of elevated left atrial pressure and arterial oxygen tension to inspired oxygen fraction $(\mathrm{PaO} / \mathrm{FiO} 2)$ less than 200. The diagnosis of ARDS requires all these features. However, as these clinical criteria do not always correlate well with diffuse alveolar damage, which is the typical pathologic ARDS feature, ARDS remains a syndrome associated with multiple diagnoses [3], rather than a disease in itself.

Despite substantial progress in understanding ARDS pathophysiology, ARDS remains a major clinical problem, and mortality is still as high as $40-46 \%$. The incidence of ARDS in the Intensive Care Unit (ICU) ranges between 4\% to $9 \%$ depending on patient age and study population [4].

\section{Pathophysiology}

Increased capillary permeability is the hallmark of ARDS. Damage of the capillary endothelium and alveolar epitheli- 
um in correlation to impaired fluid remove from the alveolar space result in accumulation of protein-rich fluid inside the alveoli, thereby producing diffuse alveolar damage, with release of pro-inflammatory cytokines, such as Tumor Necrosis Factor (TNF), IL-1 and IL-6 [5]. Neutrophils are recruited to the lungs by cytokines, become activated and release toxic mediators, such as reactive oxygen species and proteases [6]. Extensive free radical production overwhelms endogenous anti-oxidants and causes oxidative cell damage [7].

Inflammation due to neutrophil activation is key in the pathogenesis of ARDS. Fundamental transcription abnormalities, involving NF-kappa B that is required for transcription of genes for many pro-inflammatory mediators, are present in the lungs of ARDS patients [8]. In addition, other factors such as endothelin-1, angiotensin-2 and phospholipase A-2 increase vascular permeability and destroy micro-vascular architecture, enhancing inflammation and lung damage. In conclusion, as several different pathways are involved in ARDS development, no single biomarker can predict outcome in ARDS patients [9].

Computed Tomography studies in the 1980s helped us understand the pathophysiologic alterations in the lungs of ARDS patients [10]. In addition, as lung compliance correlates with the degree of the normally ventilated tissue, lung compliance decreases in ARDS because of decreased lung size, rather than because of lung stiffness, and this hypothesis introduced the concept of "baby lung" in ARDS [11].

Pulmonary hypertension $(\mathrm{PH})$ is widely recognized as a characteristic feature of ARDS [12]. PH etiology includes parenchymal destruction and airway collapse, hypoxic pulmonary vasoconstriction, presence of other pulmonary vasoconstrictors and vascular compression [13].

The initial phase of fluid accumulation is followed by a proliferation phase characterized by resolution of pulmonary edema, proliferation of type II alveolar cells, fibroblasts and myofibroblasts, and new matrix deposition. This phase starts early (within $72 \mathrm{~h}$ ) in ARDS, and lasts for more than 7 days. Factors influencing the progression to fibro-proliferation vs. resolution and reconstitution of normal pulmonary parenchymal architecture are poorly understood [14], but patients who develop pulmonary fibrosis exhibit deterioration of pulmonary compliance, progressive hypoxia and ventilator dependence, and increased mortality (> 57\%) [15].

Multiple Organ Failure (MOF) is the leading cause of death in ARDS, but the pathophysiologic link between ARDS and MOF is not well defined [16]. However, based on existing data it is not clear whether ARDS is the manifestation of a disease, or it is a disease that causes the MOF syndrome.

\section{Treatment}

Improved understanding of ARDS pathophysiology and ad- vances in technology have introduced new treatments and improved therapeutic strategies. The following paragraphs discuss recent developments in the therapeutic approach to ARDS.

\section{Low tidal volume ventilation}

The concept of "baby lung" was introduced in 1980s by Gattinoni et al and generated interest in the use of low tidal volume ventilation as therapeutic strategy in ARDS. Several animal studies showed that ventilation with large tidal volumes and high inspiratory pressures resulted in development of hyaline membranes and inflammatory infiltrates in the lungs, and development of respiratory failure [17].

In the late $1990 \mathrm{~s}$ four randomized controlled trials (RCTs) evaluated the potential benefit of low tidal volume ventilation in ARDS [18-21]. Although all four studies had limited power, one study by Amato et al [21] demonstrated that the low tidal volume group had higher survival, higher rate of weaning from mechanical ventilation and reduced rate of barotrauma.

Because of conflicting results from these studies, the National Heart Lung and Blood Institute ARDS Network conducted a multicenter RCT on 861 ARDS patients [22], comparing two group of patients ventilated with low vs. high tidal volumes. In-hospital mortality was significantly lower and the number of days without mechanical ventilation was significantly higher in the low tidal volume group. Although this study has been criticized for the high difference of tidal volume between groups, it demonstrated that high tidal volumes should be avoided, and underlined the importance of maintaining low plateau pressures, with $30 \mathrm{~cm} \mathrm{H}_{2} \mathrm{O}$ as an acceptable cut-off.

Low tidal volume ventilation is generally well tolerated and it has not been associated with clinically important adverse outcomes, except for hypercapnic respiratory acidosis in some patients. In conclusion, hypercapnia and respiratory acidosis are expected consequences of low tidal volume ventilation. However, there is no evidence that hypercapnia is harmful in ARDS patients, and it may in fact confer some protection against ventilator-associated lung injury.

\section{PEEP}

PEEP is an essential component of mechanical ventilation for patients with ARDS, as it was early observed that PEEP greatly improves oxygenation in ARDS patients. High PEEP levels may open collapsed alveoli and decrease intrapulmonary shunt. Additionally, ventilation-induced alveolar injury is reduced by decreasing alveolar over-distention, because the volume of each subsequent tidal breath is shared by more open alveoli [23]. On the other hand, high PEEP levels may decrease repetitive alveolar opening and closing during the respiratory cycle, thereby promoting lung injury [24]. 
Three RCTs have evaluated modest vs. high levels of PEEP in patients with ARDS. The NHLB ARDS Network conducted the ALVEOLI trial (Assessment of Low tidal Volume and Elevated end expiratory pressure to Obviate Lung Injury) [25]. This study showed improved $\mathrm{PaO} 2 / \mathrm{FiO} 2$ ratio but no benefits with regards to survival or duration of mechanical ventilation in the high PEEP group. Several years later, the Canadian Critical Care Trials Group performed a similar study to determine whether the combination of low tidal volume ventilation with high PEEP could improve mortality to a greater extent compared to low tidal ventilation alone [26]. Results of this study showed reduced need for other rescue therapies such as prone position or NO, but did not show any benefit in survival.

In conclusion, based on published data, high levels of PEEP do not seem to confer any benefit with regards to mortality in ARDS. Because ARDS patients are a heterogeneous population, the apparent absence of benefit from high levels of PEEP could be due to the beneficial effects of high PEEP in some ARDS patients being offset by detrimental effects in other patients [27]. However, data from the RCTs mentioned above suggest that high PEEP levels improve lungs function without any adverse effect on mortality [28].

\section{Recruitment maneuvers}

A recruitment maneuver is a transient increase of trans-pulmonary pressure intended to promote reopening of collapsed alveoli [29]. Techniques described for recruitment maneuvers include sustained high-pressure inflation and increased PEEP, with concurrent reduction of tidal volume [30], but it is not clear if any maneuver is superior to others. Several studies have shown improved gas exchange with recruitment maneuvers, but no RCT has shown benefit on ARDS mortality [31] and a recent systematic review by Fan et al [32] showed that hypotension and decreased saturation occur in $12 \%$ and $8 \%$ of patients respectively during or after such maneuvers. Based on currently available data, although routine recruitment maneuvers are not recommended in ARDS, such maneuvers can dramatically improve oxygenation in certain patients, and should be considered as rescue therapy in patients with life-threatening refractory hypoxia [33].

\section{Prone position}

Prone positioning has been used in ARDS for over 30 years. In 1976 Piehl et al. reported improved oxygenation in ARDS patients when they were turned to the prone position [34]. Since then, several observational studies on ARDS have found similar results, and improvement in oxygenation can sometimes be dramatic [35]. Mechanisms proposed to explain the observed beneficial effects of prone positioning include increased chest wall elastance decreased compression of lung tissue in the dependent regions and recruitment of alveoli, more homogeneous ventilation due to decreased ventilation-perfusion inequalities and reduced ventilator induced lung injury [36].

Four RCTs have investigated the effect of prone positioning on outcome. The first trial by the Prone-Supine Study group randomized 304 patients with a wide range of severity of acute lung injury [37].Patients remained prone for $7 \mathrm{~h} /$ day on average, for up to 10 days, but there was no effect on survival. Three years later, Guerin et al conducted a similar multicenter study [38]: patients remained prone for about 8 $\mathrm{h} /$ day, and prone positioning continued until clinical criteria for improvement were met, but this study also did not show a reduction in mortality. Two subsequent RCTs attempted to correct some shortcomings of the earlier study: they only included patients with ARDS, and patients remained prone for most of the day (about 20 h). The first RCT by Mancebo et al was terminated prematurely, after only including 142 patients, because of problems with patient recruitment [39]. A more recent multicenter RCT by Taccone et al, included 344 patients [40], and showed significantly increased frequency of adverse events (airway obstruction, hypotension, vomiting, accidental extubation) in patients treated with prone position. Neither of the last two studies showed any survival benefit using the prone position in patients with severe ARDS.

In conclusion, existing data do not support routine use of the prone position in ARDS. However, because all published studies have shown improved oxygenation, prone positioning is an attractive rescue treatment for ARDS patients with severe hypoxemia, even though a survival benefit has never been demonstrated.

\section{High-frequency ventilation}

The idea of high frequency ventilation (HFV) is to provide tidal volumes below that of anatomic dead space at high frequency ( $>60$ breaths per minute). Compared to conventional mechanical ventilation, mean airway pressure is higher [41]. Two studies, by Hamilton and Chan, showed reduced risk for barotrauma and lung over-distention, after performing high frequency ventilation [42, 43]. High frequency ventilation can be applied by different modes, such as high-frequency percussive ventilation, high-frequency jet ventilation and high-frequency oscillatory ventilation (HFOV) [44]. In the absence of studies showing superiority of one method over another, HFOV is the HFV method used more often in adult critical care [43].

In HFOV very small tidal volumes $(1-4 \mathrm{ml} / \mathrm{kg})$ are delivered at high frequency $(3-15 \mathrm{~Hz})$ by an oscillatory pump [45]. However, the use of HFOV as rescue therapy in patients with refractory hypoxia remains controversial. There are two RCTs comparing HFOV with conventional mechanical ventilation. The first RCT by Derdak et al found a trend for decreasing 30-day mortality [46] even though relatively 
high tidal volume was used in the control group. The second RCT by Bollen et al was terminated prematurely because of slow enrollment, but found an opposite trend in mortality [47]. Two meta-analyses also had conflicting results. The first one included only 2 RCTs comparing HFOV vs. conventional ventilation, and did not find any mortality reduction or improvement of oxygenation [48]. However, a more recent study by Sud et al included $8 \mathrm{RCT}$ and found reduced 30-day mortality with HFOV compared to conventional ventilation [49]. In conclusion, the role of HFOV in ARDS is not well defined, and deserves further study from well designed RCTs.

\section{Supportive treatment of ARDS}

\section{Fluid management}

Early data indicate that increased fluid administration is correlated with worse outcome in ARDS, whereas negative fluid balance was associated with better outcome [50]. The ARDS network conducted a RCT with 1000 patients randomized to receive conservative or liberal fluid administration. The conservative strategy group showed improved lung function and shortened duration of mechanical ventilation, but there was no difference in non pulmonary organ failures and 60-day mortality.

\section{Transfusions}

Allogenic blood transfusion is associated with detrimental immuno-modulatory effects that may result in ARDS [51]. Consequently, conservative transfusion strategies may decrease the incidence of ARDS.

\section{Sedation}

Several studies have shown that newer ventilation strategies using low tidal volume and high levels of PEEP do not require high doses of sedation [52]. Furthermore, evidence suggests that use of sedatives may increase duration of mechanical ventilation and ICU length of stay and may even be associated with higher mortality [53]. In addition, there is evidence that spontaneously breathing ARDS patients have improved cardiopulmonary function, presumably by recruiting non ventilated lung units [54]. Therefore, based on current evidence, avoidance or minimization of sedation and paralysis is preferred in ARDS.

\section{Neuromuscular blocking agents}

Administration of neuromuscular blocking agents (NMBA) in addition to sedation can result in improvement in severe hypoxemia, because paralysis improves patient-ventilator synchronism and reduces oxygen consumption [55]. Muscle relaxation may also improve chest wall compliance. NMBAs may also have anti-inflammatory effects that could decrease the inflammation associated with ARDS. However, because there is evidence that NMBAs increase the risk of acquired neuromuscular weakness, thereby making weaning from mechanical ventilation more difficult, and may even increase mortality [56].

\section{Nutrition}

Two RCTs [57, 58] and a meta-analysis by Puntes-Arruda et al [59] showed that administration of enteral nutrition containing high concentrations of eicosapentanoic acid and $\gamma$-linoleic acid and $\omega-3$ fatty acids increased oxygenation and decreased ICU stay and 28-day mortality in ARDS.

\section{Pharmacologic agents}

\section{Vasodilators}

Because diffuse pulmonary vasoconstriction is part of ARDS pathophysiology, selective vasodilatation of well ventilated areas seems an attractive method to improve gas exchange in ARDS patients.

Inhaled nitric oxide (iNO) causes vasodilation of ventilated lung units and redistribution of pulmonary blood flow away from non-ventilated lung areas, without adverse systemic hemodynamic effects. Four RCTs evaluated the effects of iNO and showed transient improvement in oxygenation [60-63], but no improvement in mortality. Similarly, one meta-analysis found transient oxygenation improvement but no survival benefit with iNO [64]. Consequently, iNO may be useful as short-term rescue therapy in patients with severe hypoxemic respiratory failure.

Inhaled prostacycline is another selective pulmonary vasodilator. Importantly, liposomal PGE1 influences neutrophil function and decreases neutrophil accumulation and lung leak. Although inhaled prostacycline improves oxygenation, it has not been shown to reduce duration of mechanical ventilation or mortality in ARDS patients [65]. Despite the lack of sufficient data supporting the use of prostacycline as alternative to iNO, prostacycline is increasingly used as pulmonary vasodilator, because of the high cost of iNO [66].

\section{Vasoconstrictors}

Vasoconstrictors can improve oxygenation in ARDS patients by decreasing intrapulmonary shunt. Phenylephrine [67] and almitrine [68] have been used in small studies, mainly as adjuncts during administration of NO. B-blockers have also been shown to increase arterial oxygenation in patients with ARDS [69]. However, the role of these agents in ARDS has not been adequately evaluated, and deserves further study. 


\section{Anti inflammatory agents}

The interaction between nuclear factor-kappa B (NF-kB) and glucocorticoid receptor alpha (GRa) is a key mechanism regulating the progression of systemic and pulmonary inflammation in ARDS [70]. The ability of GC-GRa to downregulate NF-kB activation is critical for the resolution of systemic and pulmonary inflammation in ARDS [71]. Although several studies showed that corticosteroids confer no benefit and may even cause harm [72], corticosteroids are still used in clinical practice.

Timing of corticosteroid administration and duration of therapy may be important, and should be taken into consideration. A RCT conducted by the ARDS Network, randomized 180 patients with persistent ( $>7$ days) ARDS, to receive methylprednisolone $(2 \mathrm{mg} / \mathrm{kg} / \mathrm{d})$ or placebo for 21 days, and showed improved oxygenation and more ventilator-free days in the methylprednisolone group, but no significant improvement in mortality [73]. Another RCT evaluated early corticosteroid administration, and showed that methylprednisolone administration (1mg/kg/d) [74] less than 72 after the onset of ARDS reduced mortality. However, these results should be interpreted with caution, because this study included a large number of patients with septic shock.

Conflicting data exist concerning the correlation between corticosteroids and ICU neuromyopathy. A sub-analysis of study survivors did not show any association between randomization to corticosteroids and increased risk of neuromyopathy [75]. In conclusion, the relationship between corticosteroids and ICU neuromyopathy is an important issue that deserves further study [76].

Several other anti-inflammatory factors like Ibuprofen [77], ketoconazole [78], neutrophil elastase inhibitors (ONO 5046) [79], NF-KB inhibitors [80], recombinant soluble complement receptor-1 [81], and liposomal prostaglandin E1 [82] have been evaluated in ARDS patients without success.

\section{Beta agonists}

There are substantial evidences that b2-agonists may play a potential role in the treatment of patients with ARDS. B2 agonists have been found to have anti-inflammatory effects by direct influence on neutrophil function and by reducing the secretion of several pro-inflammatory cytokines. Additionally, b2-agonists can reduce the endothelial permeability and stimulate the fluid clearance from the lungs [83]. In a small $\mathrm{RCT}$ using the thermodilution method (PiCCO), intravenous salbutamol $(15 \mu \mathrm{g} / \mathrm{kg} / \mathrm{h})$ use for seven days reduced extravascular lung water compared to placebo [84]. The effects of inhaled b-agonists have not, to this date, been adequately evaluated, but will be investigated in an ongoing study conducted by ARDS network (NCT00434993)

Several other pharmacological agents, including glutathione lisofylline [85], N-Acetylcysteine[86], and surfactant
[87] have been evaluated, but none of them has been shown to be effective for treatment of ARDS.

\section{Extracorporeal techniques}

Extracorporeal membrane oxygenation (ECMO) has been studied since 1970s as a method for supporting gas exchange in patients failing conventional ventilation [88]. A RCT conducted in 1979 showed that ECMO use had no effect on longterm survival of ARDS patients [89]. Nowadays, ECMO is used to support oxygenation of patients with severe ARDS, thereby allowing use of decreased ventilator settings (tidal volume, respiratory rate, $\mathrm{FiO} 2$ ), in an attempt to minimize ventilator induced lung injury.

In a more recent study 180 patients with severe ARDS were randomized to support by ECMO vs. conventional treatments. This study showed significantly improved survival $(63 \%$ vs. $47 \%, \mathrm{P}=0.03)$ at 6 months in the ECMO group [90]. Although no definite conclusions can be drawn from this study [91], the results of this study suggest that ECMO can be used as a rescue therapy in cases of very severe ARDS.

Extracorporeal $\mathrm{CO} 2$ removal $(\mathrm{ECCO} 2 \mathrm{R})$ is an alternative device that uses veno-venous circuit for removal of $\mathrm{CO} 2$ at much lower extracorporeal flow rates compared to ECMO. A RCT conducted before the year 2000 used EC$\mathrm{CO} 2 \mathrm{R}$ and showed no effect on mortality [92]. In another study ECCO2R was combined with low frequency positive pressure ventilation ( 2 - $3 \mathrm{~b} / \mathrm{min}$ ), and showed improvement in lung mechanics [93]. Overall, extracorporeal support technologies produce significant temporary improvement in ARDS patients with severe respiratory dysfunction, but this improvement does not seem to affect outcome. New, well conducted clinical studies are needed to better evaluate the role of ECMO and ECCO2R on survival in ARDS.

\section{Mortality}

Conflicting data exist about the evolution ARDS mortality over time. A meta-analysis by Phua et al did not find any mortality reduction in recent years [94], whereas another meta-analysis by Zambon et al. showed reduced mortality in recent years [4]. In the past, several studies evaluated patterns of ARDS mortality over time within the same institution [95-99], and all studies, except for two [98, 99], found decreasing mortality in ARDS. The observed discrepancy between different studies may be due to different investigational methods, but we can conclude that ARDS mortality remains high (41-46\%). Regardless of improvements in recent years, ARDS mortality is higher in older patients and in medical patients [100]. However, the impact, if any, of newer treatment strategies on ARDS mortality has not been evaluated, because most studies are referred to the period before 
the year 2000 .

\section{Conflicts of Interest}

This work was supported solely by Department funds. All authors state that they have no conflicts of interest to disclose.

\section{Abbreviations}

ARDS: Acute Respiratory Distress Syndrome; ECCO2R: Extracorporeal CO2 Removal; ECMO: Extracorporeal Membrane Oxygenation; HFV: High Frequency Ventilation; HFOV: High Frequency Oscillatory Ventilation; ICU: Intensive Care Unit; IL: Interleukin; iNO: Inhaled Nitric Oxide;MOF: Multiple Organ Failure; NMBAs: Neuromuscular Blocking Agents; PEEP: Positive End Expiratory Pressure; PH: Pulmonary Hypertension; pRBCs: Packed Red Blood Cells; RCT: Randomized Controlled Trial; TNF: Tumor Necrosis Factor; TV: Tidal Volume

\section{References}

1. Bernard GR. Acute respiratory distress syndrome: a historical perspective. Am J Respir Crit Care Med. 2005;172(7):798-806.

2. Ashbaugh DG, Bigelow DB, Petty TL, Levine BE. Acute respiratory distress in adults. Lancet. 1967;2(7511):319323.

3. Bernard GR, Artigas A, Brigham KL, Carlet J, Falke K, Hudson L, Lamy M, et al. The American-European Consensus Conference on ARDS. Definitions, mechanisms, relevant outcomes, and clinical trial coordination. Am J Respir Crit Care Med. 1994;149(3 Pt 1):818-824.

4. Zambon M, Vincent JL. Mortality rates for patients with acute lung injury/ARDS have decreased over time. Chest. 2008;133(5):1120-1127.

5. Martin TR. Lung cytokines and ARDS: Roger S. Mitchell Lecture. Chest. 1999;116(1 Suppl):2S-8S.

6. Windsor AC, Mullen PG, Fowler AA, Sugerman HJ. Role of the neutrophil in adult respiratory distress syndrome. Br J Surg. 1993;80(1):10-17.

7. Gadek JE, Pacht ER. The interdependence of lung antioxidants and antiprotease defense in ARDS. Chest. 1996;110(6 Suppl):273S-277S.

8. Moine P, McIntyre R, Schwartz MD, Kaneko D, Shenkar R, Le Tulzo Y, Moore EE, et al. NF-kappaB regulatory mechanisms in alveolar macrophages from patients with acute respiratory distress syndrome. Shock. 2000;13(2):85-91.

9. Ware LB, Koyama T, Billheimer DD, Wu W, Bernard
GR, Thompson BT, Brower RG, et al. Prognostic and pathogenetic value of combining clinical and biochemical indices in patients with acute lung injury. Chest. 2010;137(2):288-296.

10. Gattinoni L, Caironi P, Pelosi P, Goodman LR. What has computed tomography taught us about the acute respiratory distress syndrome? Am J Respir Crit Care Med. 2001;164(9):1701-1711.

11. Gattinoni L, Pelosi P, Pesenti A, Brazzi L, Vitale G, Moretto A, Crespi A, et al. CT scan in ARDS: clinical and physiopathological insights. Acta Anaesthesiol Scand Suppl. 1991;95:87-94; discussion 94-86.

12. Tomashefski JF, Jr. Pulmonary pathology of acute respiratory distress syndrome. Clin Chest Med. 2000;21(3):435-466.

13. Zapol WM, Snider MT. Pulmonary hypertension in severe acute respiratory failure. $\mathrm{N}$ Engl J Med. 1977;296(9):476-480.

14. Rocco PR, Dos Santos C, Pelosi P. Lung parenchyma remodeling in acute respiratory distress syndrome. Minerva Anestesiol. 2009;75(12):730-740.

15. Martin C, Papazian L, Payan MJ, Saux P, Gouin F. Pulmonary fibrosis correlates with outcome in adult respiratory distress syndrome. A study in mechanically ventilated patients. Chest. 1995;107(1):196-200.

16. Meduri GU, Annane D, Chrousos GP, Marik PE, Sinclair SE. Activation and regulation of systemic inflammation in ARDS: rationale for prolonged glucocorticoid therapy. Chest. 2009;136(6):1631-1643.

17. Kolobow T, Moretti MP, Fumagalli R, Mascheroni D, Prato P, Chen V, Joris M. Severe impairment in lung function induced by high peak airway pressure during mechanical ventilation. An experimental study. Am Rev Respir Dis. 1987;135(2):312-315.

18. Brower RG, Shanholtz CB, Fessler HE, Shade DM, White P, Jr., Wiener CM, Teeter JG, et al. Prospective, randomized, controlled clinical trial comparing traditional versus reduced tidal volume ventilation in acute respiratory distress syndrome patients. Crit Care Med. 1999;27(8):1492-1498.

19. Brochard L, Roudot-Thoraval F, Roupie E, Delclaux C, Chastre J, Fernandez-Mondejar E, Clementi E, et al. Tidal volume reduction for prevention of ventilator-induced lung injury in acute respiratory distress syndrome. The Multicenter Trail Group on Tidal Volume reduction in ARDS. Am J Respir Crit Care Med. 1998;158(6):18311838 .

20. Stewart TE, Meade MO, Cook DJ, Granton JT, Hodder RV, Lapinsky SE, Mazer CD, et al. Evaluation of a ventilation strategy to prevent barotrauma in patients at high risk for acute respiratory distress syndrome. Pressureand Volume-Limited Ventilation Strategy Group. N Engl J Med. 1998;338(6):355-361.

21. Amato MB, Barbas CS, Medeiros DM, Magaldi RB, 
Schettino GP, Lorenzi-Filho G, Kairalla RA, et al. Effect of a protective-ventilation strategy on mortality in the acute respiratory distress syndrome. N Engl J Med. 1998;338(6):347-354.

22. Ventilation with lower tidal volumes as compared with traditional tidal volumes for acute lung injury and the acute respiratory distress syndrome. The Acute Respiratory Distress Syndrome Network. N Engl J Med. 2000;342(18):1301-1308.

23. Gattinoni L, Pelosi P, Crotti S, Valenza F. Effects of positive end-expiratory pressure on regional distribution of tidal volume and recruitment in adult respiratory distress syndrome. Am J Respir Crit Care Med. 1995;151(6):1807-1814.

24. Caironi P, Cressoni M, Chiumello D, Ranieri M, Quintel M, Russo SG, Cornejo R, et al. Lung opening and closing during ventilation of acute respiratory distress syndrome. Am J Respir Crit Care Med. 2010;181(6):578586.

25. Brower RG, Lanken PN, MacIntyre N, Matthay MA, Morris A, Ancukiewicz M, Schoenfeld D, et al. Higher versus lower positive end-expiratory pressures in patients with the acute respiratory distress syndrome. $\mathrm{N}$ Engl J Med. 2004;351(4):327-336.

26. Meade MO, Cook DJ, Guyatt GH, Slutsky AS, Arabi YM, Cooper DJ, Davies AR, et al. Ventilation strategy using low tidal volumes, recruitment maneuvers, and high positive end-expiratory pressure for acute lung injury and acute respiratory distress syndrome: a randomized controlled trial. JAMA. 2008;299(6):637-645.

27. Grasso S, Fanelli V, Cafarelli A, Anaclerio R, Amabile M, Ancona G, Fiore T. Effects of high versus low positive end-expiratory pressures in acute respiratory distress syndrome. Am J Respir Crit Care Med. 2005;171(9):1002-1008.

28. Gattinoni L, Caironi P. Refining ventilatory treatment for acute lung injury and acute respiratory distress syndrome. JAMA. 2008;299(6):691-693.

29. Esan A, Hess DR, Raoof S, George L, Sessler CN. Severe hypoxemic respiratory failure: part 1--ventilatory strategies. Chest. 2010;137(5):1203-1216.

30. Borges JB, Okamoto VN, Matos GF, Caramez MP, Arantes PR, Barros F, Souza CE, et al. Reversibility of lung collapse and hypoxemia in early acute respiratory distress syndrome. Am J Respir Crit Care Med. 2006;174(3):268-278.

31. Gattinoni L, Caironi P, Cressoni M, Chiumello D, Ranieri VM, Quintel M, Russo S, et al. Lung recruitment in patients with the acute respiratory distress syndrome. $\mathrm{N}$ Engl J Med. 2006;354(17):1775-1786.

32. Fan E, Wilcox ME, Brower RG, Stewart TE, Mehta S, Lapinsky SE, Meade MO, et al. Recruitment maneuvers for acute lung injury: a systematic review. Am J Respir Crit Care Med. 2008;178(11):1156-1163.
33. Hodgson C, Keating JL, Holland AE, Davies AR, Smirneos L, Bradley SJ, Tuxen D. Recruitment manoeuvres for adults with acute lung injury receiving mechanical ventilation. Cochrane Database Syst Rev. 2009(2):CD006667.

34. Piehl MA, Brown RS. Use of extreme position changes in acute respiratory failure. Crit Care Med. 1976;4(1):1314.

35. Blanch L, Mancebo J, Perez M, Martinez M, Mas A, Betbese AJ, Joseph D, et al. Short-term effects of prone position in critically ill patients with acute respiratory distress syndrome. Intensive Care Med. 1997;23(10):1033-1039.

36. Gattinoni L, Carlesso E, Taccone P, Polli F, Guerin C, Mancebo J. Prone positioning improves survival in severe ARDS: a pathophysiologic review and individual patient meta-analysis. Minerva Anestesiol. 2010;76(6):448-454.

37. Gattinoni L, Tognoni G, Pesenti A, Taccone P, Mascheroni D, Labarta V, Malacrida $\mathrm{R}$, et al. Effect of prone positioning on the survival of patients with acute respiratory failure. N Engl J Med. 2001;345(8):568-573.

38. Guerin C, Gaillard S, Lemasson S, Ayzac L, Girard R, Beuret P, Palmier B, et al. Effects of systematic prone positioning in hypoxemic acute respiratory failure: a randomized controlled trial. JAMA. 2004;292(19):23792387.

39. Mancebo J, Fernandez R, Blanch L, Rialp G, Gordo F, Ferrer M, Rodriguez F, et al. A multicenter trial of prolonged prone ventilation in severe acute respiratory distress syndrome. Am J Respir Crit Care Med. 2006;173(11):1233-1239.

40. Taccone P, Pesenti A, Latini R, Polli F, Vagginelli F, Mietto C, Caspani L, et al. Prone positioning in patients with moderate and severe acute respiratory distress syndrome: a randomized controlled trial. JAMA. 2009;302(18):1977-1984.

41. dos Santos CC, Slutsky AS. Overview of high-frequency ventilation modes, clinical rationale, and gas transport mechanisms. Respir Care Clin N Am. 2001;7(4):549575.

42. Hamilton PP, Onayemi A, Smyth JA, Gillan JE, Cutz E, Froese AB, Bryan AC. Comparison of conventional and high-frequency ventilation: oxygenation and lung pathology. J Appl Physiol. 1983;55(1 Pt 1):131-138.

43. Chan KP, Stewart TE, Mehta S. High-frequency oscillatory ventilation for adult patients with ARDS. Chest. 2007;131(6):1907-1916.

44. Hess D, Mason S, Branson R. High-frequency ventilation design and equipment issues. Respir Care Clin $\mathrm{N}$ Am. 2001;7(4):577-598.

45. Rimensberger PC. ICU cornerstone: high frequency ventilation is here to stay. Crit Care. 2003;7(5):342-344.

46. Derdak S, Mehta S, Stewart TE, Smith T, Rogers M, Buchman TG, Carlin B, et al. High-frequency oscillatory 
ventilation for acute respiratory distress syndrome in adults: a randomized, controlled trial. Am J Respir Crit Care Med. 2002;166(6):801-808.

47. Bollen CW, van Well GT, Sherry T, Beale RJ, Shah S, Findlay G, Monchi M, et al. High frequency oscillatory ventilation compared with conventional mechanical ventilation in adult respiratory distress syndrome: a randomized controlled trial [ISRCTN24242669]. Crit Care. 2005;9(4):R430-439.

48. Wunsch H, Mapstone J. High-frequency ventilation versus conventional ventilation for treatment of acute lung injury and acute respiratory distress syndrome. Cochrane Database Syst Rev. 2004(1):CD004085.

49. Sud S, Sud M, Friedrich JO, Meade MO, Ferguson ND, Wunsch H, Adhikari NK. High frequency oscillation in patients with acute lung injury and acute respiratory distress syndrome (ARDS): systematic review and metaanalysis. BMJ. 2010;340:c2327.

50. Simmons RS, Berdine GG, Seidenfeld JJ, Prihoda TJ, Harris GD, Smith JD, Gilbert TJ, et al. Fluid balance and the adult respiratory distress syndrome. Am Rev Respir Dis. 1987;135(4):924-929.

51. Silliman CC, Boshkov LK, Mehdizadehkashi Z, Elzi DJ, Dickey WO, Podlosky L, Clarke G, et al. Transfusion-related acute lung injury: epidemiology and a prospective analysis of etiologic factors. Blood. 2003;101(2):454462.

52. Girard TD, Bernard GR. Mechanical ventilation in ARDS: a state-of-the-art review. Chest. 2007;131(3):921-929.

53. Kress JP, Pohlman AS, O'Connor MF, Hall JB. Daily interruption of sedative infusions in critically ill patients undergoing mechanical ventilation. $\mathrm{N}$ Engl J Med. 2000;342(20):1471-1477.

54. Putensen C, Zech S, Wrigge H, Zinserling J, Stuber F, Von Spiegel T, Mutz N. Long-term effects of spontaneous breathing during ventilatory support in patients with acute lung injury. Am J Respir Crit Care Med. 2001;164(1):43-49.

55. Gainnier M, Roch A, Forel JM, Thirion X, Arnal JM, Donati S, Papazian L. Effect of neuromuscular blocking agents on gas exchange in patients presenting with acute respiratory distress syndrome. Crit Care Med. 2004;32(1):113-119.

56. Sessler CN. Train-of-four to monitor neuromuscular blockade? Chest. 2004;126(4):1018-1022.

57. Gadek JE, DeMichele SJ, Karlstad MD, Pacht ER, Donahoe M, Albertson TE, Van Hoozen C, et al. Effect of enteral feeding with eicosapentaenoic acid, gamma-linolenic acid, and antioxidants in patients with acute respiratory distress syndrome. Enteral Nutrition in ARDS Study Group. Crit Care Med. 1999;27(8):1409-1420.

58. Pontes-Arruda A, Aragao AM, Albuquerque JD. Effects of enteral feeding with eicosapentaenoic acid, gammalinolenic acid, and antioxidants in mechanically venti- lated patients with severe sepsis and septic shock. Crit Care Med. 2006;34(9):2325-2333.

59. Pontes-Arruda A, Demichele S, Seth A, Singer P. The use of an inflammation-modulating diet in patients with acute lung injury or acute respiratory distress syndrome: a meta-analysis of outcome data. JPEN J Parenter Enteral Nutr. 2008;32(6):596-605.

60. Michael JR, Barton RG, Saffle JR, Mone M, Markewitz BA, Hillier K, Elstad MR, et al. Inhaled nitric oxide versus conventional therapy: effect on oxygenation in ARDS. Am J Respir Crit Care Med. 1998;157(5 Pt 1):1372-1380.

61. Taylor RW, Zimmerman JL, Dellinger RP, Straube RC, Criner GJ, Davis K, Jr., Kelly KM, et al. Low-dose inhaled nitric oxide in patients with acute lung injury: a randomized controlled trial. JAMA. 2004;291(13):16031609.

62. Dellinger RP, Zimmerman JL, Taylor RW, Straube RC, Hauser DL, Criner GJ, Davis K, Jr., et al. Effects of inhaled nitric oxide in patients with acute respiratory distress syndrome: results of a randomized phase II trial. Inhaled Nitric Oxide in ARDS Study Group. Crit Care Med. 1998;26(1):15-23.

63. Troncy E, Collet JP, Shapiro S, Guimond JG, Blair L, Ducruet T, Francoeur M, et al. Inhaled nitric oxide in acute respiratory distress syndrome: a pilot randomized controlled study. Am J Respir Crit Care Med. 1998;157(5 Pt 1):1483-1488.

64. Adhikari NK, Burns KE, Friedrich JO, Granton JT, Cook DJ, Meade MO. Effect of nitric oxide on oxygenation and mortality in acute lung injury: systematic review and meta-analysis. BMJ. 2007;334(7597):779.

65. Heard SO, Longtine K, Toth I, Puyana JC, Potenza B, Smyrnios N. The influence of liposome-encapsulated prostaglandin E1 on hydrogen peroxide concentrations in the exhaled breath of patients with the acute respiratory distress syndrome. Anesth Analg. 1999;89(2):353357.

66. Siobal MS. Pulmonary vasodilators. Respir Care. 2007;52(7):885-899.

67. Doering EB, Hanson CW, 3rd, Reily DJ, Marshall C, Marshall BE. Improvement in oxygenation by phenylephrine and nitric oxide in patients with adult respiratory distress syndrome. Anesthesiology. 1997;87(1):18-25.

68. Roch A, Papazian L, Bregeon F, Gainnier M, Michelet P, Thirion X, Saux P, et al. High or low doses of almitrine bismesylate in ARDS patients responding to inhaled $\mathrm{NO}$ and receiving norepinephrine? Intensive Care Med. 2001;27(11):1737-1743.

69. Vincent JL, Lignian H, Gillet JB, Berre J, Contu E. Increase in $\mathrm{PaO} 2$ following intravenous administration of propranolol in acutely hypoxemic patients. Chest. 1985;88(4):558-562.

70. von Bismarck P, Klemm K, Garcia Wistadt CF, Winoto- 
Morbach S, Schutze S, Krause MF. Selective NF-kappaB inhibition, but not dexamethasone, decreases acute lung injury in a newborn piglet airway inflammation model. Pulm Pharmacol Ther. 2009;22(4):297-304.

71. Meduri GU, Muthiah MP, Carratu P, Eltorky M, Chrousos GP. Nuclear factor-kappaB- and glucocorticoid receptor alpha- mediated mechanisms in the regulation of systemic and pulmonary inflammation during sepsis and acute respiratory distress syndrome. Evidence for inflammation-induced target tissue resistance to glucocorticoids. Neuroimmunomodulation. 2005;12(6):321338.

72. Bernard GR, Luce JM, Sprung CL, Rinaldo JE, Tate RM, Sibbald WJ, Kariman K, et al. High-dose corticosteroids in patients with the adult respiratory distress syndrome. N Engl J Med. 1987;317(25):1565-1570.

73. Steinberg KP, Hudson LD, Goodman RB, Hough CL, Lanken PN, Hyzy R, Thompson BT, et al. Efficacy and safety of corticosteroids for persistent acute respiratory distress syndrome. N Engl J Med. 2006;354(16):16711684.

74. Meduri GU, Golden E, Freire AX, Taylor E, Zaman M, Carson SJ, Gibson M, et al. Methylprednisolone infusion in early severe ARDS: results of a randomized controlled trial. Chest. 2007;131(4):954-963.

75. Hough CL, Steinberg KP, Taylor Thompson B, Rubenfeld GD, Hudson LD. Intensive care unit-acquired neuromyopathy and corticosteroids in survivors of persistent ARDS. Intensive Care Med. 2009;35(1):63-68.

76. Meduri GU, Marik PE, Chrousos GP, Pastores SM, Arlt W, Beishuizen A, Bokhari F, et al. Steroid treatment in ARDS: a critical appraisal of the ARDS network trial and the recent literature. Intensive Care Med. 2008;34(1):61-69.

77. Bernard GR, Wheeler AP, Russell JA, Schein R, Summer WR, Steinberg KP, Fulkerson WJ, et al. The effects of ibuprofen on the physiology and survival of patients with sepsis. The Ibuprofen in Sepsis Study Group. N Engl J Med. 1997;336(13):912-918.

78. Ketoconazole for early treatment of acute lung injury and acute respiratory distress syndrome: a randomized controlled trial. The ARDS Network. JAMA. 2000;283(15):1995-2002.

79. Kadoi Y, Hinohara H, Kunimoto F, Saito S, Goto F, Kosaka T, Ieta K. Pilot study of the effects of ONO-5046 in patients with acute respiratory distress syndrome. Anesth Analg. 2004;99(3):872-877, table of contents.

80. Lee HS, Lee JM, Kim MS, Kim HY, Hwangbo B, Zo JI. Low-dose steroid therapy at an early phase of postoperative acute respiratory distress syndrome. Ann Thorac Surg. 2005;79(2):405-410.

81. Zimmerman JL, Dellinger RP, Straube RC, Levin JL. Phase I trial of the recombinant soluble complement receptor 1 in acute lung injury and acute respiratory dis- tress syndrome. Crit Care Med. 2000;28(9):3149-3154.

82. Vincent JL, Brase R, Santman F, Suter PM, McLuckie A, Dhainaut JF, Park Y, et al. A multi-centre, double-blind, placebo-controlled study of liposomal prostaglandin E1 (TLC C-53) in patients with acute respiratory distress syndrome. Intensive Care Med. 2001;27(10):1578-1583.

83. Perkins GD, Gao F, Thickett DR. In vivo and in vitro effects of salbutamol on alveolar epithelial repair in acute lung injury. Thorax. 2008;63(3):215-220.

84. Perkins GD, McAuley DF, Thickett DR, Gao F. The beta-agonist lung injury trial (BALTI): a randomized placebo-controlled clinical trial. Am J Respir Crit Care Med. 2006;173(3):281-287.

85. Randomized, placebo-controlled trial of lisofylline for early treatment of acute lung injury and acute respiratory distress syndrome. Crit Care Med. 2002;30(1):1-6.

86. Moradi M, Mojtahedzadeh M, Mandegari A, SoltanSharifi MS, Najafi A, Khajavi MR, Hajibabayee M, et al. The role of glutathione-S-transferase polymorphisms on clinical outcome of ALI/ARDS patient treated with N-acetylcysteine. Respir Med. 2009;103(3):434-441.

87. Spragg RG, Lewis JF, Walmrath HD, Johannigman J, Bellingan G, Laterre PF, Witte MC, et al. Effect of recombinant surfactant protein C-based surfactant on the acute respiratory distress syndrome. N Engl J Med. 2004;351(9):884-892.

88. Newland PE. Extracorporeal membrane oxygenation in the treatment of respiratory failure--a review. Anaesth Intensive Care. 1977;5(2):99-112.

89. Zapol WM, Snider MT, Hill JD, Fallat RJ, Bartlett $\mathrm{RH}$, Edmunds LH, Morris AH, et al. Extracorporeal membrane oxygenation in severe acute respiratory failure. A randomized prospective study. JAMA. 1979;242(20):2193-2196.

90. Peek GJ, Elbourne D, Mugford M, Tiruvoipati R, Wilson A, Allen E, Clemens F, et al. Randomised controlled trial and parallel economic evaluation of conventional ventilatory support versus extracorporeal membrane oxygenation for severe adult respiratory failure (CESAR). Health Technol Assess. 2010;14(35):1-46.

91. Moran JL, Chalwin RP, Graham PL. Extracorporeal membrane oxygenation (ECMO) reconsidered. Crit Care Resusc. 2010;12(2):131-135.

92. Morris AH, Wallace CJ, Menlove RL, Clemmer TP, Orme JF, Jr., Weaver LK, Dean NC, et al. Randomized clinical trial of pressure-controlled inverse ratio ventilation and extracorporeal $\mathrm{CO} 2$ removal for adult respiratory distress syndrome. Am J Respir Crit Care Med. 1994;149(2 Pt 1):295-305.

93. Gattinoni L, Pesenti A, Mascheroni D, Marcolin R, Fumagalli R, Rossi F, Iapichino G, et al. Low-frequency positive-pressure ventilation with extracorporeal $\mathrm{CO} 2$ removal in severe acute respiratory failure. JAMA. 1986;256(7):881-886. 
94. Phua J, Badia JR, Adhikari NK, Friedrich JO, Fowler RA, Singh JM, Scales DC, et al. Has mortality from acute respiratory distress syndrome decreased over time?: A systematic review. Am J Respir Crit Care Med. 2009;179(3):220-227.

95. Milberg JA, Davis DR, Steinberg KP, Hudson LD. Improved survival of patients with acute respiratory distress syndrome (ARDS): 1983-1993. JAMA. 1995;273(4):306-309.

96. Abel SJ, Finney SJ, Brett SJ, Keogh BF, Morgan CJ, Evans TW. Reduced mortality in association with the acute respiratory distress syndrome (ARDS). Thorax. 1998;53(4):292-294.

97. Stapleton RD, Wang BM, Hudson LD, Rubenfeld GD,
Caldwell ES, Steinberg KP. Causes and timing of death in patients with ARDS. Chest. 2005;128(2):525-532.

98. Eachempati SR, Hydo LJ, Shou J, Barie PS. Outcomes of acute respiratory distress syndrome (ARDS) in elderly patients. J Trauma. 2007;63(2):344-350.

99. Navarrete-Navarro P, Rodriguez A, Reynolds N, West R, Habashi N, Rivera R, Chiu WC, et al. Acute respiratory distress syndrome among trauma patients: trends in ICU mortality, risk factors, complications and resource utilization. Intensive Care Med. 2001;27(7):1133-1140.

100.Suchyta MR, Clemmer TP, Elliott CG, Orme JF, Jr., Morris AH, Jacobson J, Menlove R. Increased mortality of older patients with acute respiratory distress syndrome. Chest. 1997;111(5):1334-1339. 